\title{
Tracing Volcanic Events in the Greenland Ice Cores
}

S.M. Davies ${ }^{1}$, A.K. Mortensen ${ }^{2}$, M.G.L. Baillie ${ }^{3}$, H.B. Clausen ${ }^{4}$, K. Grönvold ${ }^{2}$, V.A. Hall ${ }^{3}$, S.J. Johnsen ${ }^{4}$, J.R. Pilcher ${ }^{3}$, J.P. SteFFensen ${ }^{4}$ AND S. WASTEGÅRd 5

1Department of Geography, University of Wales Swansea, Singleton Park, Swansea, SA2 8PP, UK; siwan.davies@swansea.ac.uk ${ }^{2}$ Nordic Volcanological Institute, Askja, University of Iceland, Sturlugata 7, 101 Reykjavik, Iceland; akm@hi.is; karlgr@hi.is

${ }^{3}$ School of Archaeology and Palaeoecology, Queen's University of Belfast, Northern Ireland, BT7 1NN; v.hall@qub.ac.uk; j.pilcher@qub.ac.uk; m.baillie@qub.ac.uk

4Department of Geophysics, University of Copenhagen, 2100 Copenhagen Ø, Denmark; hbc@gfy.ku.dk; sigfus@gfy.ku.dk; jps@gfy.ku.dk ${ }^{5}$ Department of Physical Geography and Quaternary Geology, Stockholm University, 10691 Stockholm, Sweden; stefan.wastegard@geo.su.se

Although tephrochronology has long been employed as a correlation tool for a broad range of Quaternary sequences, it is only recently that advances in the detection of cryptotephra horizons (tephra horizons that are invisible to the naked eye) have changed the scope and potential of this technique to address paleoclimatic investigations. Identification of distinct cryptotephra horizons in regions not traditionally associated with tephrochronological research has considerably extended the geographical distribution of some tephras, thus emphasizing the potential of using such time-parallel marker horizons for precise correlation of sequences on a continent-wide scale (e.g., Turney et al., 2004). In recent years, investigations in Europe have focused upon the employment of this technique for the improvement of chronological models and for correlative purposes during Termination 1 and the early Holocene $\left(18-9{ }^{14} \mathrm{C}\right.$ ka BP) - a period characterized by abrupt and rapid climatic events and plagued by dating uncertainties (Lowe et al., 2001). Indeed, the use of tephrochronology is one of the recommendations made by the INTIMATE and SCOTAV groups for enabling precise correlations of terrestrial, marine and ice core records during this period, with the overall aim of testing hypotheses of synchronous climate change (Turney et al., 2004).

Crucial to this work is a detailed investigation of the tephra record contained within the annually resolved Greenland ice-core records. Chemical signals in the ice, such as sulfate and electrical conductivity measurements (ECM), can be used to construct a detailed volcanic history (Hammer et al., 1981; Zielinski et al., 1996). The origin of such signals remains uncertain however, without the extraction and geochemical analysis



Fig. 1: A 1-cm-thick visible tephra horizon identified within the NGRIP record.

of volcanic glass shards contained within the ice. Two important marker horizons of Termination 1 age-the Vedde and Saksunarvatn Tephraswere identified within the GRIP core during the mid 1990s (Grönvold et al., 1995) and represent the only tephras to be traced in terrestrial, marine and ice-core sequences, thus serving as important tie-points. Tephra layers from other periods, such as the Settlement layer and the Ash Zone 2 layer, have also been identified within the GRIP and GISP2 records (Zielinski et al., 1997), but a large proportion of these records remain essentially untouched in terms of tephrochronology and more specifically cryptotephra investigations. Indeed, the detailed Late Quaternary tephrochronology frameworks for the different volcanic regions of Europe (e.g., Haflidason et al., 2000; Davies et al., 2002) accentuate the importance of fully exploring the Greenland tephra records for the presence of tephra horizons.

In recent years, teams from the University of Wales Swansea, University of Reykjavik, Queen's University Belfast and Stockholm University, in collaboration with the University of Copenhagen, have begun detailed screening of the GRIP and NGRIP cores for the presence of distinct tephra horizons. Different time periods are currently being investigated by the various teams with the aim of pinpointing key marker horizons that have been previously detected within terrestrial and marine records, as well as examining the detailed volcanic history contained within these records. A portion of this work is undertaken under the remit of the Copenhagen Ice Core Dating Initiative and up until now has focused upon the tephra record spanning the last 30,000 GRIP ice-core yrs BP.

\section{Cryptotephra Extraction}

The latest screening of the Greenland ice cores has revealed an abundance of tephra. In some cases, 1-cm-thick tephra horizons have been identified by the naked eye (Fig. 1). In other cases, however, only a few shards, often between $20-40 \mu \mathrm{m}$ in size and occasionally no more than 5-15 $\mu \mathrm{m}$ (Fig. 2), are present and thus careful extraction and manipulation techniques must be employed to ensure the acquisition of meaningful geochemical results. Tracing the occurrence of cryptotephras therefore relies upon the use of chemical indicators, e.g., sulfate, calcium and ECM data. Often these are useful guides for cryptotephra detection, although in some cases tephra horizons are not accompanied by distinct chemical signatures and vice versa.

Careful subsampling of the archived material is undertaken once a specific horizon has been pinpointed 


\section{Science Highlights: Tephra}

using the high-resolution ice-core chemical data. All particulate material is extracted from the melted sample of ice by centrifugation and is subsequently prepared onto glass slides or SEM stubs. A combination of SEM and light microscopy is used to identify any volcanic particles that may be present and careful thin section preparations are then undertaken to prepare the slide for electron microprobe analysis. Wavelength dispersive spectrometry is utilized to derive the major oxide composition of each tephra. This process is vital for the identification of the source volcano and to ensure accurate correlation with tephras found within other climate records. Precise and standardized geochemical procedures are thus fundamental for the effective use of tephrochronology. Occasionally, geochemical analysis of these tephras can be problematic, particularly as the shard size and the low concentration of shards within some samples can hamper data acquisition. Careful point selection and adequate shard thickness is crucial in these instances.

\section{Ice Core Tephrochronology}

Thus far, detailed investigation of the NGRIP sequence has not only revealed the presence of some key marker horizons, e.g., Vedde and Saksunarvatn Tephras, but several previously undiscovered tephras have also been identified. In total, therefore, 12 tephra layers have been identified in the NGRIP record during Termination 1 (Mortensen et al., submitted). Their geochemical compositions point towards Iceland as the most likely volcanic source, although in some cases the major oxide results preclude the precise identification of the source. More distal volcanic regions such as Alaska, the Cascades and Japan must also be considered. Investigations of the GRIP sequence have also revealed the presence of 4 tephra layers that can be correlated with tephras identified within the NGRIP record and as such are important tie-points between the two records that are located $300 \mathrm{~km}$ apart. The value of tephrochronology as a correlation tool is clearly demonstrated in this respect. The significance
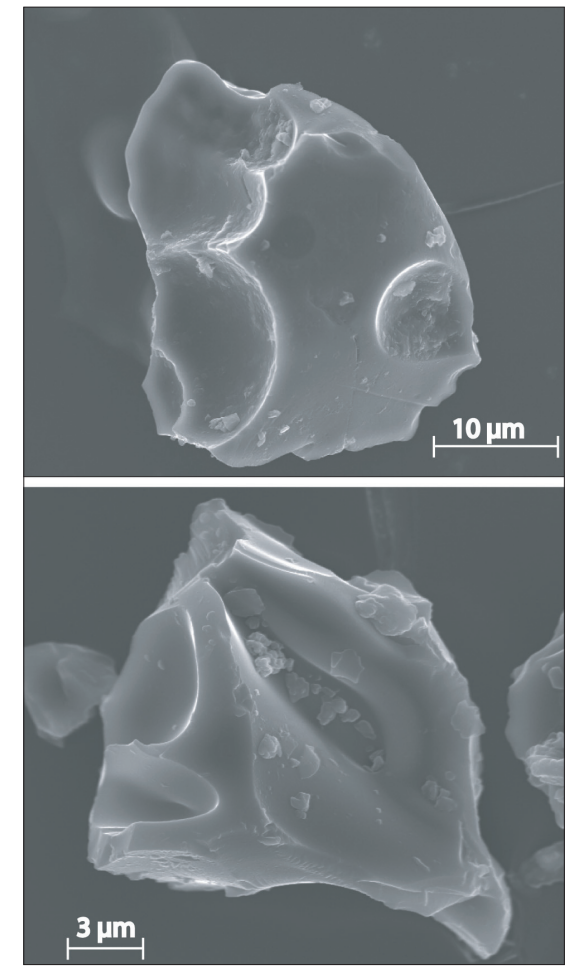

Fig. 2: Scanning electron microscope images of tephra shards extracted from the NGRIP and GRIP records.

and potential of these new tephras as time-parallel marker horizons in the North Atlantic region, however, is uncertain until their presence can be detected elsewhere and the likely distribution pattern identified.

Intense investigations are ongoing to assess whether some of the key Termination 1 marker horizons, e.g., Laacher See (LST) and Borrobol Tephras, that are widely dispersed in other climatic records of Termination 1 age in Europe, occur within the NGRIP and the more-southerly GRIP record. If their position can be pinpointed within these records, this would open up a number of possibilities for correlation with, e.g., annually resolved records in central Europe where the LST is prominent (Litt et al., 2001) and for resolving a number of dating issues that surround the BorrobolTephra in terrestrial and marine records (Davies et al., 2004).

\section{Future Investigations}

Selective screening of the GRIP and NGRIP cores has so far demonstrated that our knowledge of the Icelandic tephrochronology framework is far from complete and the temporal resolution offered by the Greenland records is unmatched for this objective. Consequently, the Greenland tephra record will provide exceptional insight into the eruptive frequency of specific volcanic centers as well as the magnitude and nature of each eruption. The search continues, however, for some of the more well-known marker horizons within the Holocene, Termination 1 and preceding periods that are found within marine and terrestrial records in Europe. Detection of key tie-points between the different records will enable hypotheses of synchronous climate change to be tested, as well as resolving some of the dating uncertainties (e.g., marine reservoir corrections) that hamper paleoclimate investigations during the Late Quaternary.

\section{ACKNOWLEDGEMENTS}

The NGRIP deep drilling project is directed and organized by the Department of Geophysics at the Niels Bohr Institute for Astronomy, Physics and Geophysics, University of Copenhagen. It is supported by funding agencies in Denmark (SNF), Belgium (FNRS-CFB), France (IPEV and INSU/CNRS), Germany (AWI), Iceland (Rannls), Japan (MEXT), Sweden (SPRS), Switzerland (SNF) and the USA (NSF, Office of Polar Programs). The Copenhagen Ice Core Dating Initiative is a 5-year project funded by the Carlsberg Foundation and conducted at the Department of Geophysics, University of Copenhagen. The project involves absolute dating of the NGRIP core and correlation with other paleoclimatic archives using tephra horizons.

\section{References}

Davies, S.M., Branch, N.P., Lowe, J.J. and Turney, C.S.M., 2002: Towards a European tephrochronological framework for Termination 1 and the early Holocene. Philosophical Transactions of the Royal Society of London Series A 360, 767-802.

Grönvold, K., Oskarsson, N., Johnsen, S.J., Clausen, H.B., Hammer, C.U., Bond, G. and Bard, E., 1995: Ash layers from Iceland in the GRIP ice core correlated with oceanic and land sediments. Earth and Planetary Science Letters 135, 149-155.

Mortensen, A.K., Bigler, M., Grönvold, K., Steffensen, J.P. and Johnsen, S. J.: Ash layers from the Last Glacial Termination in the NGRIP ice core. Journal of Quaternary Science., submitted

Turney, C.S.M., Lowe, J.J., Davies, S.M., Hall, V.A. Lowe, D.J., Wastegård, S., Hoek, W.Z., Alloway, B., SCOTAV and INTIMATE members, 2004:

Tephrochronology of Last Termination sequences in Europe: a protocol for improved analytical precision and robust correlation procedures (a joint SCOTAV-INTIMATE proposal). Journal of Quaternary Science 19, 111-120.

Zielinski, G.A., Mayewski, P.A., Meeker, L.D., Gronvöld, K., Germani, M.S., Whitlow, S., Twickler M.S. and Taylor, K., 1997: Volcanic aerosol records and tephrochronology of the Summit, Greenland, ice cores. Journal of Geophysical Research 102, 26,625-26,640.

For full references please consult: www.pages-igbp.org/products/newsletters/ref2004_3.html 